\title{
Habilidade metalinguística pragmática em crianças em idade escolar
}

\author{
Pragmatic metalinguistic ability in school age children
}

Talita dos Santos Gonçalves ${ }^{1}$

Doutoranda do Programa de Pós-Graduação em Letras da PUCRS, área de concentração em Linguística. Bolsa Capes. E-mail: talitafpele@gmail.com
RESUM0: Este estudo encontra-se no espaço de interação entre estudos da Psicolinguística, no que diz respeito à consciência metalinguística pragmática; e em estudos da Pragmática Inferencial, no que tange à compreensão do dêitico 'aqui' e de um ato de fala ilocutório/perlocutório direto. O objetivo foi traçar uma reflexão sobre o comportamento metalinguístico pragmático de crianças em idade escolar em relação à compreensão de uma promessa em tom de ameaça e um mecanismo de localização espacial do diálogo. Essa habilidade metalinguística consiste na capacidade de o indivíduo refletir sobre os aspectos contextuais que determinam o uso da língua, bem como de manipular informações advindas dessa relação (GOMBERT, 1992). Por exemplo, para compreender um ato de fala, os falantes se apoiam tanto em informações linguísticas quanto no contexto onde a interação verbal ocorre. 0 ato de fala ilocucionário (AUSTIN, 1962; SEARLE, 1979, 1981) é um exemplo dessa relação, já que o contexto e as informações linguísticas determinam/desencadeiam a realização de uma ação. Além desse exemplo, o uso de dêixis de lugar (LEVINSON, 2007) indica a localização onde ocorre a interação verbal, permitindo observar a relação entre o enunciado e o contexto de onde se fala. Os participantes da pesquisa são oito crianças entre sete e dez anos de idade, alunos de uma escola municipal da cidade de Jaguarão/RS. Como instrumento, foi aplicada uma tarefa contendo duas situações interativas, adaptadas de uma investigação sobre o processamento inferencial e a compreensão de implícitos (FLÔRES et al., 2013). A maioria dos participantes foi ineficiente na apreensão das informações contextuais, principalmente do ato de fala de promessa. Em relação à compreensão do dêitico 'aqui', os participantes utilizaram as informações contextuais para justificar suas escolhas. De um modo geral, este trabalho, pretende auxiliar nas reflexões sobre as habilidades metalinguísticas em crianças e também contribuir com discussões no campo da Pragmática.

PalAVRAS-CHAVE: Consciência metapragmática; Pragmática inferencial; Crianças.

ABSTRACT: This study lies within the interaction between Psycholinguistic studies, with regard to the pragmatic metalinguistic awareness; and on the Inferential Pragmatic studies regarding the understanding of deictic 'here' and a direct illocutionary/perlocutionary speech act. The aim was to outline a reflection on the pragmatic metalinguistic behavior of school age children in relation to the realization of a promise in a threatening tone and spatial localization mechanism of dialogue. This meta-linguistic ability is the individual's ability to reflect on the contextual aspects that determine the use of language, as well as to manipulate information arising from this relationship (GOMBERT, 1992). For example, to understand a speech act, speakers rely on linguistic information and in the context where verbal interaction occurs. The illocutionary speech act is an example of this relationship, as the context and language information determines/trigger performing an action. In this example, the use of deixis place (LEVINSON, 2007) indicates the location where the verbal interaction occurs, allowing to observe the relationship between the utterance and the 
context where speech. The participants are eight children between seven and ten years old, students of a municipal school in the city of Jaguarão/ RS. As an instrument, was applied a task containing two interactive situations, adapted from an investigation into the inferential processing and understanding of implicit (FLÔRES et al., 2013). Most of the participants were inefficient in the appropriation of contextual information, especially the act speech of promise. Regarding the understanding of deictic 'here', participants used contextual information to justify their choices. In general, this work intends to assist in reflections on the metalinguistic skills in children and contribute to discussions in the field of Pragmatics.

KEYwords: Metapragmatic awareness; Inferential Pragmatic, Children.

\section{Introdução}

$\mathrm{T}$ rata-se, neste artigo, do conhecimento que crianças em idade escolar apresentam sobre o contexto em que diálogos ocorrem, tendo como material de análise duas interações verbais. Esta investigação constrói-se na interface entre estudos da Psicolinguística, no que diz respeito à consciência ${ }^{1}$ metalinguística pragmática ou consciência metapragmática; e em estudos da Pragmática Inferencial, no que tange à compreensão do dêitico 'aqui' e de um ato de fala ilocucionário/perlocutório direto. 0 objetivo é traçar uma reflexão sobre o comportamento metalinguístico pragmático de crianças de sete a dez anos em relação à compreensão de uma promessa em tom de ameaça e um mecanismo de localização espacial do diálogo.

Este artigo está organizado em seções e subseções. Primeiramente, será apresentada a fundamentação teórica que embasa o estudo, explanando individualmente cada temática envolvida na interface proposta para, posteriormente, estabelecer um ponto de encontro entre elas. Para ilustrar essa interação entre áreas, será exibido, na seção seguinte, um experimento

${ }^{1}$ Na literatura psicolinguística nacional e internacional, o conceito de 'consciência' utilizado advém da Psicologia Cognitiva Contudo, há uma discussão no uso desse termo juntamente com o prefixo 'meta' cm 'metalinúch ser evitado já que tal prefixo pressupõe 'consciencia' no seu significado. Este trabalhado assúá terminologia corrente na literatura psicolinguística. realizado com crianças de sete a dez anos de uma escola pública. Em seguida, os resultados serão elencados e discutidos. Para finalizar este trabalho, pondera-se sobre a convergência das áreas envolvidas e retomam-se os principais resultados.

\section{Fundamentação teórica}

\subsection{Consciência metalinguística: habilidade pragmática}

A consciência metalinguística é um construto estudado pela Psicolinguística e pela Psicologia Cognitiva, por si só já é um tema estudado em interface. Em uma perspectiva ampla, a consciência metalinguística trata da reflexão sobre os aspectos da língua. Conforme Tunmer, Pratt e Herriman (1984), a língua torna-se objeto do pensamento. Essa consciência envolve diversos tipos de habilidades, a saber: segmentar e manipular a língua em suas diferentes unidades, desde o fonema até o texto; compreender as diferenças entre significados e significantes, além de julgar a coerência sintática e semântica de sentenças e enunciados. Em suma, essa reflexão é uma habilidade desenvolvida em todos os níveis da língua: fonológico, morfológico, sintático, lexical, semântico, textual e pragmático.

Antes da alfabetização, a criança é capaz de utilizar a língua como instrumento para a comunicação, pois essa habilidade é adquirida 
naturalmente através da interação social. Além disso, antes de qualquer instrução formal, a criança é capaz de refletir sobre os aspectos formais da língua, cada um ao seu tempo no desenvolvimento cognitivo infantil. Segundo Barreira e Maluf (2003), evidências mostram que crianças ainda não alfabetizadas conseguem analisar unidades suprassegmentais, mas a habilidade de manipular fonemas é mais bem desenvolvida durante o processo de alfabetização, através do contato com o sistema escrito. Outras habilidades surgem posteriormente, como é o caso da habilidade metalinguística pragmática, que será considerada neste trabalho.

Estudos sobre a consciência metapragmática são escassos e sua metodologia ainda é incipiente, por isso torna-se um tema aberto a ponderações. Inicialmente, deve-se considerar seu conceito. Para Gombert (1992), essa habilidade metalinguística consiste na capacidade do indivíduo de refletir sobre os aspectos contextuais que determinam o uso da língua, bem como de manipular informações advindas dessa relação. De um modo geral, a consciência metapragmática refere-se não apenas às relações dentro do sistema linguístico, mas também aquelas entre o sistema e o contexto/situação de uso da língua - locutor e alocutário, objetivo e suporte comunicativo, tempo e espaço da comunicação.

Como se observa, a habilidade metapragmática abarca muito mais do que componentes do sistema linguístico. De acordo com Chaves e Lopes (2012, p.28), pesquisas nesse tema concentram-se especialmente em três habilidades, a saber: a) perceber a ambiguidade nas mensagens; b) detectar incoerências nas mensagens; e c) alterar seu comportamento discursivo em virtude das especificidades da interação comunicativa.

Em relação ao desenvolvimento dessa habilidade durante a infância, conforme Gombert (1992), as crianças adquirem a consciência metapragmática em diferentes momentos. Inicialmente, a criança passa por uma fase epipragmática² ${ }^{2}$ que consiste no desenvolvimento de atividades de controle sobre a produção e a compreensão da linguagem oral, relacionandoas a elementos extralinguísticos. Esse controle seria inconsciente, pois não haveria a reflexão e a verbalização próprias da habilidade metapragmática (CRESPO; ALFARO, 2009, p. 230). Em geral, nessa fase, a criança não discrimina explicitamente entre o que é linguístico e o que não é.

A fase metapragmática se inicia aproximadamente aos seis anos de idade e envolve a consciência verbalizável da diferença entre o linguístico e o contextual. Em consequência disso, surgiria o controle reflexivo dessa relação em uma determinada interação comunicativa. A criança é capaz de explicar as relações entre forma linguística e contexto na produção e compreensão das mensagens, além de compreender metáforas e ironia.

Segundo Gombert (1992), o acesso à fase metapragmática está ligado ao aumento da capacidade de memória de trabalho ${ }^{3}$. Por isso, a habilidade metapragmática não é empregada de maneira sistemática a todas as situações, pois a criança poderá oscilar entre comportamentos metapragmáticos e epipragmáticos. Para Crespo e Alfaro (2009), o controle consciente característico dessa fase não se desenvolve apenas com a idade, já que uma criança de seis anos não apresenta respostas metapragmáticas a todo o momento, a resposta irá depender da complexidade da interação verbal.

Para Verschueren (2002), os indicadores da consciência metapragmática funcionam de três maneiras no uso linguístico, a saber: a) como mecanismos de ancoragem que localizam formas linguísticas em relação ao contexto (dêiticos e pronomes); b) como marcadores de interpretação reflexiva dos

${ }^{2}$ Conforme Crespo e Alfaro (2009), O prefixo 'epi' refere-se a um "trabalho sobre” a língua. Esse trabalho seria indispensável para ir além do uso instrumental da língua.

3 De acordo consável para (2009) em tarefas cognitivas como na compreensão da linguagem e no raciocínio. 
falantes com respeito às atividades que realizam (advérbios oracionais); e c) como chaves de contextualização (mudanças prosódicas, gestos e sons).

Considerando o exposto acima, pretende-se refletir sobre o comportamento metalinguístico pragmático de crianças de sete a dez anos em relação à compreensão de uma promessa em tom de ameaça e um mecanismo de localização espacial do diálogo. Para isso, as próximas subseções tratarão, sob uma perspectiva pragmática, de Atos de Fala e do dêitico de lugar 'aqui'.

\subsection{Atos de Fala}

A Teoria dos Atos de Fala desenvolvida por John Austin, na década de sessenta do século passado, e ampliada por John Searle, propõe que a linguagem é uma forma de ação. Primeiramente, surge a reflexão sobre os diferentes tipos de ações humanas realizadas a partir da linguagem. Austin questiona a visão descritivista da língua, mostrando que certas afirmações realizam ações e não apenas descrevem um estado das coisas.

Para Austin (1962), toda utilização da língua é um ato de fala, um ato realizado pelo falante. A Pragmática analisa os atos de fala considerando uma dupla função dos enunciados, o ato de declarar e o ato de fazer coisas com a linguagem. $O$ autor (1962) denominou esses atos, como: a) ato locucionário; b) ato ilocucionário; e c) ato perlocucionário. 0 primeiro é o ato de dizer ou afirmar algo com sentido e com referência, o segundo é o ato de fazer algo através do ato anterior e o último ato se refere à consequência do ato anterior.

Outra contribuição de Austin para a Teoria dos Atos de Fala é a noção de performatividade. Performativos são os verbos que realizam as ações além de as nomearem, como, por exemplo, "jurar", "outorgar", "prometer", entre tantos outros que carregam uma força ilocucionária. São verbos enunciados de forma afirmativa, na primeira pessoa do singular do presente do indicativo e na voz ativa. No enunciado "Eu juro", o falante (na primeira pessoa do singular do presente do indicativo) está nomeando e realizando uma ação simultaneamente, assim como ocorre nos exemplos, a seguir:

(1) Eu outorgo-te o grau de licenciado em Letras.

(2) Eu juro que voltarei.

(3) Eu vos declaro casados.

No entanto, enunciar um verbo performativo não garante a sua realização. Para que haja a realização de um ato performativo, algumas circunstâncias precisam ser adequadas para sua efetivação. Por exemplo, o enunciado (1) só se realiza efetivamente se for enunciado por um/a reitor/a ou por uma pessoa investida no cargo, designada oficialmente e com antecedência, em uma cerimônia de colação de grau. Caso contrário, o ato performativo não se realiza, pois as circunstâncias são inadequadas.

Segundo Austin (1962), um ato de fala é concomitantemente locucionário, ilocucionário e perlocucionário. Em outras palavras, quando se enuncia "Eu outorgo-te o grau de licenciado em Letras”, tem-se um ato locucionário ao enunciar os elementos linguísticos que compõem a frase. Ao mesmo tempo, tem-se um ato ilocucionário, pois ao enunciar realiza-se na linguagem a outorga de grau. Por outro lado, tem-se também um ato perlocucionário, pois o resultado de enunciar é uma concessão de direito.

Searle $(1979,1981)$ retomou e sistematizou essas noções, distinguindo-as em cinco grupos de atos de fala, a saber:

a) Atos representativos - evidenciam as crenças do locutor sobre o conteúdo de uma proposição, que pode ser tomado como verdadeiro ou falso. Ex: dizer, afirmar;

b) Atos diretivos - induzem o alocutário a desempenhar uma ação. Ex: ordenar, solicitar; 
c) Atos comissivos - implicam uma ação futura do locutor. Ex: garantir, prometer;

d) Atos expressivos - divulgam sentimentos. Ex: perdoar, agradecer;

e) Atos declarativos - determinam uma situação nova. Ex: nomear, demitir, aprovar.

Além desses grupos, os atos de fala foram divididos em diretos e indiretos. Um ato de fala realizado através de pergunta, de ordens e de pedidos, por exemplo, é um ato de fala direto. Já um ato de fala realizado indiretamente por meio de outro tipo de ato de fala torna-se indireto. A seguir são apresentados exemplos desses atos de fala:

(4) Onde fica a biblioteca? - Ato de fala direto

(5) Você sabe onde fica a biblioteca? - Ato de fala indireto

De um modo geral, a Teoria dos Atos de Fala incluiu elementos do contexto nos estudos linguísticos. A partir dessa teoria, passou-se a observar o locutor, o alocutário, o objetivo da mensagem, bem como quando e onde se realiza a mensagem, a fim de buscar pistas que auxiliem a compreensão do enunciado. Os atos de fala são um campo fértil de estudos tanto na Pragmática como em outras áreas que apresentem convergências. Nesse sentido, este trabalho irá refletir sobre a compreensão de um ato de fala (comissivo e direto), além do dêitico de lugar 'aqui', apresentado na seção seguinte.

\subsection{Dêixis}

Em geral, a dêixis ${ }^{4}$ é um mecanismo que serve para relacionar o enunciado à situação comunicativa em que se realiza. Esse mecanismo indica a localização e a identificação do locutor e do alocutário, do objetivo,

4 "Dêixis" é uma palavra de origem grega e carrega em o sentido de "apontar" ou "indicar". do momento e do lugar onde se realiza a interação verbal. Consoante Levinson (2007), seu estudo encontra-se na fronteira entre a Pragmática e a Semântica. Grosso modo, a dêixis marca as circunstâncias do enunciado através de cinco categorias, a saber: pessoa, tempo, lugar, discurso e dinâmica social.

Para Levinson (2007), a dêixis se configura de maneira egocêntrica, pois há uma pessoa central que enuncia; um tempo central em que o locutor produz o enunciado; e existe um lugar central onde o locutor está localizado. Além disso, conforme o autor (2007), a dêixis não indica um referente fixo no mundo, mas funciona como um roteiro para se conhecer um referente dentro da enunciação. A seguir é explanado como a dêixis é codificada em língua portuguesa ${ }^{5}$.

Especificamente, a dêixis de pessoa refere-se aos elementos linguísticos que apontam os participantes no momento da interação verbal. A referência à pessoa é codificada por meio de pessoas gramaticais. $O$ locutor é a primeira pessoa gramaticalizada (Eu). A segunda pessoa gramatical é o alocutário (Tu), enquanto a terceira pessoa refere-se tanto a pessoas quanto a objetos (Ele/a) a que se destina o enunciado e que não se confundem com o locutor ou o alocutário dentro da enunciação.

A dêixis de tempo é codificada como pontos de expansão temporal em relação ao momento em que um enunciado foi produzido. A marcação de tempo distingue-se em tempo de produção e tempo de recepção, que podem coincidir ou não. Para Lyons (1977), quando essas marcações temporais acontecem concomitantemente, esse momento denomina-se de simultaneidade dêitica. Por isso, durante a interpretação de enunciados com dêixis temporal, é necessário definir se a referência permanece no locutor (tempo de produção) ou projeta-se ao alocutário (tempo de recepção).

${ }^{5}$ A dêixis varia conforme a língua. 
Por sua vez, a dêixis de lugar refere-se à localização do locutor em relação ao alocutário, ao enunciar. Essa localização pode ser de proximidade ou de distância. Em outras palavras, esse tipo de dêitico ancora o lugar dos participantes na situação comunicativa, bem como de objetos ou pontos de referência. Os pronomes demonstrativos (este/a e esse/a, aquele/a) e os advérbios de lugar (aqui, ali, lá) são exemplos típicos de dêixis de lugar.

Esses elementos linguísticos combinados com elementos não dêiticos de organização do espaço fornecem descrições de localização. São exemplos de descritores de localização as diferenças entre espaços, superfícies, recipientes, o que está à frente e atrás, o que está em cima e o que está embaixo. Para Levinson (2007), alguns verbos de movimento têm componentes dêiticos incorporados, como é o caso dos verbos "vir" e "ir".

Além dessas categorias dêiticas, de acordo com Levinson (2007), há outras duas categorias de dêixis: a discursiva e a social. A primeira sinaliza partes do discurso ao longo da interação, enquanto a segunda marca as distinções sociais entre os envolvidos na interação verbal, um em relação ao outro. $O$ autor (2007) ainda cria uma categoria de dêixis conforme sua modalidade de uso: a gestual e a simbólica. A dêixis gestual ocorre através do gesto como elemento que orienta a interação comunicativa. Já a dêixis simbólica ocorre por meio do conhecimento espaço-temporal compartilhado entre os participantes.

Após explanar brevemente sobre esse tema tão produtivo dentro da Pragmática e da Semântica, propõe-se ponderar sobre como crianças em idade escolar compreendem o dêitico espacial 'aqui' em uma interação verbal. $\mathrm{O}$ experimento realizado com a compreensão do dêitico espacial, bem como a compreensão de um ato de fala comissivo será apresentado na seção que segue.

\section{0 experimento}

O objetivo deste trabalho foi refletir sobre o comportamento metalinguístico pragmático de crianças de oito a dez anos em relação à compreensão de uma promessa em tom de ameaça (ato de fala comissivo diretivo) e um mecanismo de localização espacial (dêitico 'aqui') do diálogo.

Nesta seção, retomam-se algumas noções expostas ao longo deste artigo para, posteriormente, descrever o método do experimento. Primeiro, a noção de habilidade metapragmática. A consciência metapragmática referese à habilidade para manipular e refletir sobre relações advindas do interior do sistema linguístico, bem como aquelas entre esse sistema e o contexto da interação verbal. Para tal, é necessário que se leve em consideração os aspectos envolvidos na situação comunicativa, como o locutor e o alocutário, o objetivo e o suporte comunicativo, o tempo e o espaço da comunicação, entre outros elementos.

Para atingir essa consciência o falante desenvolve desde a infância percepções sobre a interação verbal, que vão se ampliando conforme seu repertório de situações comunicativas vai aumentando. Nesse repertório de interação social e verbal, o falante se depara com inúmeras situações comunicativas distintas, com informações linguísticas e contextuais explícitas e implícitas, que contribuirão para a compreensão da mensagem. O falante terá êxito na sua compreensão se tiver condições de utilizar essas informações a seu favor.

Como exemplo de informações linguísticas e contextuais, citam-se os atos de fala e os dêiticos. Pragmaticamente, os atos de fala são tipos de ações humanas realizadas a partir da linguagem, como declarar algo sobre o mundo e fazer algo com a língua. Esse segundo tipo de ação, de interesse deste estudo, configura-se através de verbos performativos, que além de nomearem, realizam uma ação. $\mathrm{O}$ exemplo de verbo performativo utilizado 
no estudo é o "jurar". Em relação à dêixis, entende-se como um mecanismo que indica a localização e a identificação dos elementos que compõem a interação verbal: locutor e alocutário, objetivo, momento e lugar. O dêitico de lugar 'aqui' é posto em análise neste trabalho.

0 ponto de convergência das áreas destacadas encontra-se na capacidade do falante de refletir sobre informações do contexto da situação comunicativa, mais especificamente, sobre o ato de fala comissivo e o dêitico 'aqui', utilizando-as como suporte para a compreensão da mensagem. Para ilustrar essa convergência, apresenta-se o experimento que segue.

\subsection{Participantes}

Fizeram parte deste estudo oito crianças com idade entre sete e dez anos de idade. As crianças foram recrutadas, aleatoriamente, em uma escola pública da cidade de Jaguarão/RS. Não houve controle do status socioeconômico ou controle de proficiência leitora dos participantes. Antes da aplicação da tarefa, os responsáveis pelas crianças leram e assinaram um termo de autorização.

\subsection{Instrumento}

Com base na tarefa elaborada por Flôres et al. (2013), foram selecionadas duas situações interativas dentre as dez apresentadas nesse estudo. Essas duas interações foram adaptadas para este instrumento. Cada situação contém duas questões de múltipla escolha e uma figura que representa a situação (ANEXO I). A adaptação dessa tarefa consiste na solicitação de uma justificativa para a opção escolhida.

\subsection{Procedimentos}

A tarefa foi apresentada individualmente aos participantes em única seção. $\mathrm{O}$ avaliador convidou o participante a acompanhar a leitura da situação e observar sua figura correspondente. Logo após a leitura do diálogo, o avaliador leu uma questão por vez, bem como suas opções de resposta. Ao final, após o participante ter escolhido sua resposta dentre as opções, o avaliador perguntou 'por que' e anotou a justificativa de tal escolha. Como se observa, o participante não teve que escrever nenhuma resposta.

\section{Resultados}

Antes de apresentar os resultados para cada questão, mostram-se as situações interativas.

\section{a) Situação 1}

A mãe e o filho estão na cozinha. Ela, então, lhe diz:

Mãe: Vinícius, se não parar de comer desse jeito, juro que te dou uns tapas! Logo em seguida, Vinícius enche novamente a boca de doce e a mãe lhe dá um tapão.

Essa primeira situação foi utilizada para observar o conhecimento dos participantes ao compreender o ato de fala comissivo direto de "jurar/ ameaçar" em "juro que te dou uns tapas!". A seguir, as questões e as respostas são apresentadas.

\section{Questão 1 - Primeiro, a mãe do Vinícius:}

a) Ameaçou o garoto.

b) Pediu-lhe um favor.

c) Disse que ele era malcriado.

d) Ofereceu-lhe um docinho.

Justificativa: 
Quadro 1. Respostas para a questão 1 da Situação 1

\begin{tabular}{|c|l|l|l|}
\hline Participantes & Idade & \multicolumn{1}{|c|}{ Opção escolhida } & \multicolumn{1}{|c|}{ Justificativa } \\
\hline 1 & 7 anos & d) Ofereceu-lhe um docinho. & Porque ele parou de comer. \\
\hline 2 & 7 anos & a) Ameaçou o garoto. & Porque eu li. \\
\hline 3 & 8 anos & c) Disse que ele era malcriado. & Porque ele estava comendo com a mão. \\
\hline 4 & 8 anos & d) Ofereceu-lhe um docinho. & Porque senão ela vai dar "pau" nele. \\
\hline 5 & 8 anos & c) Disse que ele era malcriado. & Porque ele comia os doces. \\
\hline 6 & 8 anos & c) Disse que ele era malcriado. & Porque ela ficou brava. \\
\hline 7 & 9 anos & a) Ameaçou o garoto. & $\begin{array}{l}\text { Porque a mãe disse que não era pra } \\
\text { seguir comendo os doces e ele seguiu } \\
\text { comendo e ela deu um tapa. }\end{array}$ \\
\hline 8 & 10 anos & a) Ameaçou o garoto. & $\begin{array}{l}\text { Porque ela disse para ele comer direito } \\
\text { ele não comeu. }\end{array}$ \\
\hline
\end{tabular}

\section{Questão 2 - Em seguida, o que fez a mãe do Vinícius:}

a) Deu-lhe um xingão.

b) Deu-lhe um tapa.

c) Deu-lhe conselhos.

d) Fez-lhe um agrado.

Justificativa:

Quadro 2. Respostas para a questão 2 da Situação 1

\begin{tabular}{|c|l|l|l|}
\hline Participantes & Idade & \multicolumn{1}{|c|}{ Opção de escolha } & \multicolumn{1}{|c|}{ Justificativa } \\
\hline 1 & 7 anos & d) Fez-lhe um agrado. & Porque ele parou de comer. \\
\hline 2 & 7 anos & b) Deu-lhe um tapa. & Porque ele é teimoso. \\
\hline 3 & 8 anos & b) Deu-lhe um tapa. & Porque ele comeu com a mão. \\
\hline 4 & 8 anos & b) Deu-lhe um tapa. & Porque deu um tapa. \\
\hline 5 & 8 anos & b) Deu-lhe um tapa. & Porque ele tava teimando. \\
\hline 6 & 8 anos & b) Deu-lhe um tapa. & $\begin{array}{l}\text { Ele apanhou porque não era pra } \\
\text { comer. }\end{array}$ \\
\hline 7 & 9 anos & b) Deu-lhe um tapa. & Porque a mãe avisou antes. \\
\hline 8 & 10 anos & b) Deu-lhe um tapa. & Porque ele não obedeceu. \\
\hline
\end{tabular}

\section{b) Situação 2}

Dois meninos discutem sobre qual deverá ser a próxima brincadeira

Marcos: Luciano, vamo joga bola?

Luciano: Não. Quero joga vídeo game.

Marcos: Ah... meu! Vamos brincar aqui!

A segunda situação foi utilizada para observar o conhecimento dos participantes ao compreender o dêitico de lugar 'aqui' em "Ah... meu! Vamos brincar aqui!". A seguir, as questões e as respostas são apresentadas.

\section{Questão 1 - O que o primeiro garoto quer?}

a) Jogar vídeo game.

b) Jogar futebol.

c) Ir ao shopping.

d) Pescar com um amigo.

Justificativa:

Quadro 3. Respostas para a questão 1 da Situação 2

\begin{tabular}{|c|l|l|l|}
\hline Participantes & Idade & \multicolumn{1}{|c|}{ Opção de escolha } & \multicolumn{1}{|c|}{ Justificativa } \\
\hline 1 & 7 anos & a) Jogar vídeo game. & Porque ele gosta de jogar. \\
\hline 2 & 7 anos & b) Jogar futebol. & Porque diz no texto. \\
\hline 3 & 8 anos & a) Jogar vídeo game. & Porque são amigos. \\
\hline 4 & 8 anos & b) Jogar futebol. & Porque ele quer jogar bola. \\
\hline 5 & 8 anos & b) Jogar futebol. & Porque eles gostavam de jogar futebol. \\
\hline 6 & 8 anos & b) Jogar futebol. & Porque ele quer jogar bola. \\
\hline 7 & 9 anos & b) Jogar futebol. & $\begin{array}{l}\text { Porque ele está com equipamento de } \\
\text { futebol. }\end{array}$ \\
\hline 8 & 10 anos & b) Jogar futebol. & Porque ele disse. \\
\hline
\end{tabular}




\section{Questão 2 - Onde Marcos quer brincar?}

a) No corredor.

b) No quarto.

c) No pátio.

d) Na escola.

Justificativa:

Quadro 4. Respostas para a questão 2 da Situação 2

\begin{tabular}{|c|l|l|l|}
\hline Participantes & Idade & \multicolumn{1}{|c|}{ Opção } & \multicolumn{1}{c|}{ Justificativa } \\
\hline 1 & 7 anos & c) No pátio. & $\begin{array}{l}\text { Porque eles estão aqui no pátio } \\
\text { (aponta para a figura) }\end{array}$ \\
\hline 2 & 7 anos & c) No pátio. & Pela imagem. \\
\hline 3 & 8 anos & c) No pátio. & Porque ele gosta de brincar fora. \\
\hline 4 & 8 anos & b) No quarto. & Não sei. \\
\hline 5 & 8 anos & c) No pátio. & Porque ele quer jogar futebol. \\
\hline 6 & 8 anos & c) No pátio. & Porque ele gosta de brincar na escola. \\
\hline 7 & 9 anos & c) No pátio. & Porque eles estão no campo. \\
\hline 8 & 10 anos & c) No pátio. & Porque eles estão no pátio. \\
\hline & &
\end{tabular}

\section{Discussão}

\subsection{Situação 1}

$\mathrm{Na}$ primeira questão, observa-se que apenas três participantes escolheram a opção que se referia à ameaça. Outros três indicaram que a mãe do garoto "disse que ele era malcriado", mesmo que esse conteúdo não aparecesse no diálogo. $\mathrm{O}$ mesmo ocorreu com dois participantes que indicaram a opção "ofereceu-lhe um docinho". São muitas possibilidades de interpretação dessas respostas: ou os participantes não acompanharam a leitura da situação, ou se fixaram na figura, ou associaram a situação com alguma experiência anterior. Aqueles que indicaram a "ameaça" variam nas idades, pois não foram apenas as crianças mais velhas que compreenderam a "ameaça".

Em relação às justificativas, houve aquelas sem coerência nenhuma com a opção escolhida, como é o caso das respostas dos participantes que escolheram a opção (d). Já entre os participantes que escolheram a opção (c), dois deles compreenderam que o garoto era mal-educado porque comia os doces (com a mão) e porque a mãe ficou brava. A percepção do estado da mãe com certeza foi identificado pelas informações visuais indicadas na figura que ilustra a situação comunicativa. As justificativas apresentadas pelos participantes que identificaram a ameaça variam entre as informações que o participante leu explicitamente no texto (Porque eu li) e pela compreensão da situação que motivou a ameaça.

Na segunda questão, apenas um participante de sete anos indicou que a mãe fez um agrado ao garoto, talvez essa resposta tenha sido motivada somente pela visualização da figura e não pelas informações da situação comunicativa. Os demais participantes indicaram o cumprimento da ameaça da mãe.

As justificativas circularam entre a atitude do menino de não parar de comer os doces (ele comeu com a mão, não era para comer) e a atitude de rejeitar a ameaça da mãe (ele é teimoso, tava teimando e não obedeceu), além da informação explícita no texto (Porque deu um tapa), até a compreensão de que a ameaça foi cumprida porque foi avisada de antemão. Nessa última justificativa, percebemos que o participante de nove anos verificou que o ato de fala "jurar" realiza a promessa de uma ação futura e essa ação (ameaça) se concretiza pelo não cumprimento das condições impostas pela mãe. No geral, observa-se que a maioria das crianças compreende que a ação de 'dar um tapa' resulta do comportamento do menino e não do ato de fala (ilocutório e perlocutório) enunciado pela mãe. Do ponto de vista metalinguís- 
tico, percebe-se que apenas o participante de nove anos pensou sobre a ameaça.

\subsection{Situação 2}

Na primeira questão, dois participantes indicaram que primeiro garoto a falar "quer jogar vídeo-game". Essa resposta pode ser associada ao fato de o jogo ser mencionado por último no diálogo e ser a informação mais recente na memória. Os demais participantes identificaram que o primeiro garoto a falar no diálogo quer 'jogar futebol'.

As justificativas são de diferentes índoles e parecem estar fundamentadas na experiência pessoal dos participantes. Os dois participantes que responderam diferentemente dos demais justificam suas respostas dizendo que o locutor gosta de jogar e que o locutor e alocutário são amigos. A maioria dos participantes compreende a escolha do jogo porque o locutor quer jogar, gostava de jogar, estava com equipamento de futebol. Essa última inferência pode ter surgido porque os personagens, que ilustram o diálogo, estão vestidos com roupas parecidas com uniformes de jogadores. Além dessas justificativas, há duas que mencionam que a escolha do jogo está no texto e porque ele disse. Em geral, nota-se que os participantes se apoiaram em informações extratextuais para justificar sua resposta, exceto as duas crianças que buscaram a informação no texto.

Na segunda questão, apenas dois participantes não identificaram a localização espacial onde ocorre o diálogo. Um deles chegou a dar uma resposta e uma justificativa que mostram que o participante não estava atento à leitura ou à figura ilustrativa. $\mathrm{O}$ outro indica na escola, porque ele gosta de brincar na escola. O participante pode ter escolhido essa opção de resposta, porque deve ter experiências com o pátio da escola e isso deve ter influenciado sua resposta, de alguma maneira. Os demais participantes compreendem que o lugar "aqui" refere-se ao pátio, pois a figura mostra o locutor e o alocutário ao ar livre. Nesse caso, a maioria dos participantes conseguiu relacionar o conteúdo do enunciado ao lugar onde foi produzido, indicando a compreensão do dêitico 'aqui'.

As justificativas dadas pela maioria dos participantes para essa questão mostram o verbo 'estar' (estão no pátio, estão aqui no pátio, estão no campo), no sentido de encontrar-se em um lugar. Isso reforça o entendimento do dêitico 'aqui' que funciona como uma marca de lugar. Para grande parte dos participantes, a justificativa dada fundamentou-se na informação visual, que pode ser tanto um pátio de escola, um pátio de casa, um campo ou qualquer lugar fora de um ambiente fechado. Dois participantes usam explicitamente a figura para comprovar sua resposta (pela imagem, aqui no pátio, apontando a figura).

Algumas justificativas são interessantes, como a do Participante 5, que menciona pátio, porque ele quer jogar bola. Nesse caso, a justificativa não é um lugar, mas o desejo de jogar bola, que na sua experiência pessoal deve acontecer no pátio. Outras justificativas interessantes são: ele gosta de brincar fora e ele gosta de brincar na escola, indicando que os participantes entendem que o 'pátio' é lugar de brincadeira. Em síntese, os participantes buscam informações extratextuais para compreender o dêitico 'aqui', evidenciando seu conhecimento metalinguístico pragmático.

Após a apresentação desse experimento ilustrativo, apresentam-se algumas considerações finais.

\section{Considerações finais}

Na tentativa de estabelecer um diálogo entre a habilidade metapragmática e algumas noções da Pragmática, percebeu-se que há, por natureza, uma convergência entre essas áreas, pois a Pragmática é discutida sob duas perspectivas. A primeira como um dos níveis que compõem a língua, investigada a partir da consciência metalinguística, enquanto a segunda, a partir de um ponto de vista amplo, como Teoria Pragmática. 
O objetivo deste trabalho foi traçar uma reflexão sobre o comportamento metalinguístico pragmático de crianças de sete a dez anos em relação à compreensão de uma promessa em tom de ameaça e um mecanismo de localização espacial do diálogo. Para tal, propôs-se um instrumento composto por duas situações de comunicação.

Em suma, os resultados mostram que a primeira situação apresentou as respostas mais díspares, pois apenas três crianças conseguiram compreender a promessa ameaçadora contida no diálogo. No entanto, a maioria dos participantes indicou ter compreendido que a promessa foi cumprida pela mãe e que a ação de 'dar um tapa' foi consequência do comportamento do menino, e não da promessa realizada pela mãe.

Em relação à segunda questão, a maioria dos participantes identificou que quem queria jogar futebol era o primeiro garoto a falar no diálogo. Percebe-se que as informações extratextuais, principalmente as experiências pessoais, auxiliaram na escolha da resposta. Além disso, os participantes compreenderam o dêitico 'aqui' como sendo um mecanismo que sinaliza o referente 'pátio', apresentado na figura que ilustra essa situação interativa, mostrando ter algum grau de conhecimento metapragmático.

De um modo geral, este trabalho, buscou auxiliar nas reflexões sobre as habilidades metalinguísticas, principalmente as pragmáticas, em crianças de sete a dez anos de idade e contribuir com discussões no campo da Pragmática e da Psicolinguística.

\section{Referências}

AUSTIN, John Langshaw. How to do things with words. Oxford: Claredon Press, 1962.

BARRERA, Sylvia; MALUF, Maria Regina. Consciência metalinguística e alfabetização: um estudo com crianças da primeira série do ensino fundamental. Psicologia: Reflexão e Crítica, v. 16, n. 3, p. 491-502, 2003. http://dx.doi.org/10.1590/S0102-79722003000300008
CHAVES, Jésura; LOPES, Marília. Metacognição e Metalinguagem. Estudos sobre Leitura: Psicolinguística e interfaces. Porto Alegre: EdiPucrs, 2012, p. 21-30.

CRESPO, Nina; ALFARO, Pedro. Desarrollo tardío del lenguaje: la conciencia metapragmática en la edad escolar. Javeriana, v. 9, n. 1, p. 229-240, 2009.

FLÔRES, Onici Claro; HUBNER, Lilian Cristine; GABRIEL, Rosângela. Processo inferencial e leitura de implícitos nos anos iniciais. Nonada, v. 2, n. 21, 2013.

GOMBERT, Jean. Metalinguistic development. Chicago: University of Chicago Press, 1992. LEVINSON, Stephen. Pragmática. Trad. Luís Carlos Borges e Aníbal Mari. São Paulo: Martins Fontes, 2007

LYONS, John. Semantics. Cambridge: University Press. 1977. Vol. 2.

POERSH, Marcelino. Implicações da consciência linguística no processo ensino/ aprendizagem da linguagem. Psycholinguistics on the threshold of the year 2000: Proceedings of the 5th International Congress of the International Society of Applied Psycholinguistics. Porto, Faculdade de Letras da Universidade do Porto, 1999.

SEARLE, John R. Expression and meaning. Cambridge: Cambridge University Press, 1979. . Os actos de fala: um ensaio de filosofia da linguagem. Coimbra: Almedina, 1981.

TUNMER, Willian. PRATT, Christopher. HERRIMAN, Michel (Orgs.). Metalinguistic awareness in children: theory, research and implications. Nova York: Springer-Verlag 1984. http://dx.doi.org/10.1007/978-3-642-69113-3

VERSCHUEREN, Jef. Para entender la Pragmática. Madrid: Gredos, 2002.

Recebido em 09/11/2015 Aceito em $11 / 12 / 2015$ 
ANEXO

Situação 1

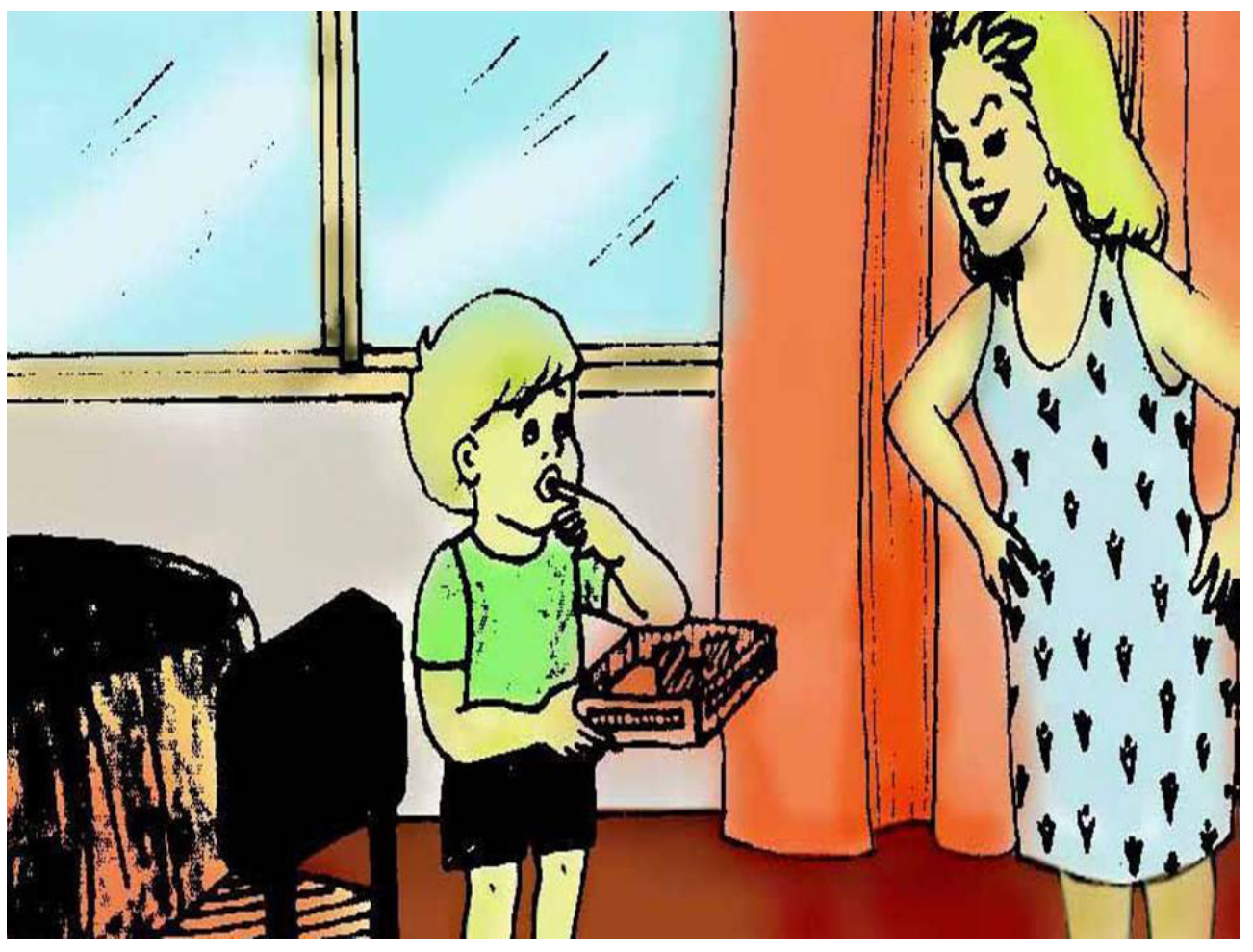

Fonte: FLÔRES et al.; 2013
Situação 2

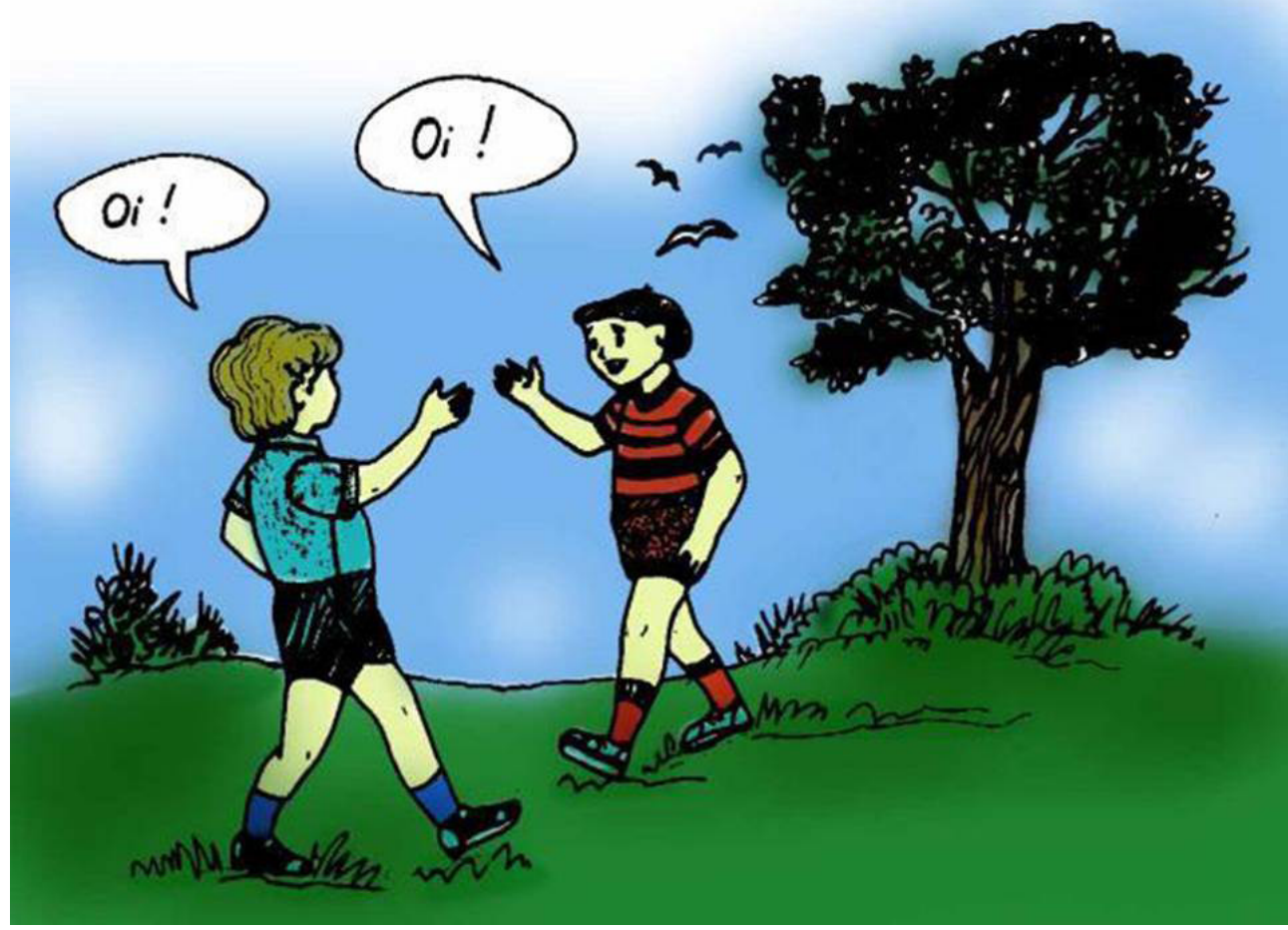

Fonte: FLÔRES et al.; 2013 